\title{
The relationship between size and longevity of the malaria vector Anopheles gambiae (s.s.) depends on the larval environment
}

\author{
Antoine M. G. Barreaux ${ }^{1,2^{*}}$ (D), Chris M. Stone ${ }^{3}$, Priscille Barreaux ${ }^{1,2}$ and Jacob C. Koella ${ }^{2}$
}

\begin{abstract}
Background: Understanding the variation in vector-borne disease transmission intensity across time and space relies on a thorough understanding of the impact of environmental factors on vectorial capacity traits of mosquito populations. This is driven primarily by variation in larval development and growth, with carryover effects influencing adult traits such as longevity and adult body size. The relationship between body size and longevity strongly affects the evolution of life histories and the epidemiology of vector-borne diseases. This relationship ranges from positive to negative but the reasons for this variability are not clear. Both traits depend on a number of environmental factors, but primarily on temperature as well as availability of nutritional resources. We therefore asked how the larval environment of the mosquito Anopheles gambiae Giles (sensu stricto) (Diptera: Culicidae) affects the relationship between body size and longevity.
\end{abstract}

Methods: We reared the larvae of An. gambiae individually at three temperatures $\left(21,25\right.$ and $\left.29^{\circ} \mathrm{C}\right)$ and two food levels (the standard and $50 \%$ of our laboratory diet) and measured adult size and longevity. We estimated the direct and indirect (via adult size) effects of food and temperature on longevity with a piecewise structural equation model (SEM).

Results: We confirmed the direct effects of food and temperature during larval development on body size, as wing length decreased with increasing temperature and decreasing food levels. While the overall relationship between size and longevity was weak, we measured striking differences among environments. At $25^{\circ} \mathrm{C}$ there was no clear relationship between size and longevity; at $29^{\circ} \mathrm{C}$ the association was negative with standard food but positive with low food; whereas at $21^{\circ} \mathrm{C}$ it was positive with standard food but negative with low food.

Conclusions: The larval environment influences the adult's fitness in complex ways with larger mosquitoes living longer in some environments but not in others. This confirmed our hypothesis that the relationship between size and longevity is not limited to a positive correlation. A better understanding of this relationship and its mechanisms may improve the modelling of the transmission of vector borne diseases, the evolution of life history traits, and the influence of vector control.

Keywords: Anopheles gambiae, Body size, Larval environment, Longevity, Mosquito life history, Piece-wise structural equation modelling

\footnotetext{
* Correspondence: antoine.barreaux@gmail.com

${ }^{1}$ Center for Infectious Disease Dynamics and Department of Entomology,

Pennsylvania State University, University Park, PA 16802, USA

${ }^{2}$ Laboratory of Ecology and Epidemiology of Parasites, Institute of Biology,

University of Neuchâtel, Rue Emile-Argand 11, 2000 Neuchâtel, Switzerland

Full list of author information is available at the end of the article
}

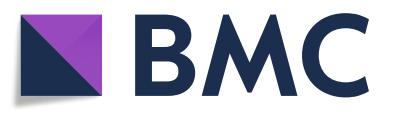

(c) The Author(s). 2018 Open Access This article is distributed under the terms of the Creative Commons Attribution 4.0 International License (http://creativecommons.org/licenses/by/4.0/), which permits unrestricted use, distribution, and reproduction in any medium, provided you give appropriate credit to the original author(s) and the source, provide a link to the Creative Commons license, and indicate if changes were made. The Creative Commons Public Domain Dedication waiver (http://creativecommons.org/publicdomain/zero/1.0/) applies to the data made available in this article, unless otherwise stated. 


\section{Background}

Understanding the variation in vector-borne disease transmission intensity across time and space relies on a thorough understanding of the effect of environmental factors on vectorial capacity traits of mosquito populations. A major area of interest, for instance, has been on understanding the effect of temperature on vectorial capacity [1], although a wide range of environmental and anthropogenic factors impacts mosquito populations [2].

Fluctuations in mosquito population size are driven primarily by variation in larval development and growth, with direct consequences for vector-borne disease transmission. Additionally, carryover effects from the larval stage can influence vectorial capacity traits such as longevity, fertility, vector competence and biting behavior [3-5].

Larval growth and development of mosquitoes, as well as life history traits such as the body size of adults, depends on a number of environmental factors, but primarily on temperature as well as availability of nutritional resources (whether due to lower abundance in the habitat or resulting from resource competition) [4, 6-9]. Considering just the impacts on larval growth, foraging behavior, and survival of several of these factors simultaneously can quickly become complex [7, 10-13]. The consequences of such interactions between extrinsic factors experienced during the larval stage on adult traits has received much less attention but becomes important if one wishes to move beyond considering the effect of one environmental variable in isolation, to predictions under field conditions.

For epidemiological models to consider more than one environmental variable at the time, it would be useful if the combined effects of temperature and larval resource quality or density could be considered through a shared metric. Similar approaches have been used to great effect in a variety of systems where a continuous trait, such as body size, has a strong relation to a number of life history traits and individual fitness [14]. In mosquitoes, adult body size is affected by temperature and resource levels and could putatively play such a role. We know relatively little however of the relation between mosquito body size and adult longevity, particularly whether variation in size resulting from different extrinsic factors leads to different outcomes. We focus on longevity as it is a major determinant of evolutionary fitness [15]. In mosquitoes, longevity, along with the biting rate, has the strongest influence on vectorial capacity $[16,17]$.

We expect longevity to be positively correlated with body size as a larger mosquito should emerge with larger teneral reserves [18] and larger mosquitoes are also more efficient in accumulating reserves from blood meals [19]. While it is true that longevity often increases with body size $[19,20]$, this correlation is not always apparent $[4,21]$ and can even be negative $[9,22]$. One of the reasons for this variation may be that survival and adult body size respond differently to environmental factors. For example, undernourished juveniles generally become small adults [23] with increased longevity $[9,24]$, so that we expect a negative correlation between the two traits among environments. In contrast, colder temperature generally leads to larger adults [7] that live longer, in cold-blooded animals [25], giving a positive correlation. We expect the slope of the correlation between adult body size and longevity to change depending on the larval environment and we do not know how the interaction of two different environmental factors, larval diet and larval temperature, may influence this correlation of two traits that respond differently to these environmental factors.

We more formally investigate how two environmental factors (temperature and nutrition levels during larval development) that both influence adult size and longevity, affect the association between these two traits of epidemiological relevance in an important vector of human malaria, Anopheles gambiae. To do so, we reared $A n$. gambiae mosquitoes at three different larval temperatures $\left(21,25\right.$ and $29{ }^{\circ} \mathrm{C}$ ) and two food levels (the standard and $50 \%$ of our laboratory diet), let the adult females blood feed and measured their size and their longevity.

\section{Methods}

Newly hatched larvae from our Kisumu colony of Anopheles gambiae Giles (s.s.), were placed individually in 12-well-plates (VWR International S.a.r.l., Nyon, Switzerland), with each well containing one larva in $3 \mathrm{ml}$ of deionised water. The well-plates were placed inside incubators and the larvae were reared at constant temperatures, at 21,25 or $29{ }^{\circ} \mathrm{C}, 70 \pm 5 \% \mathrm{RH}$ and a $12: 12 \mathrm{~h}$ light:dark cycle. The larvae were fed our standard diet or $50 \%$ of it. Each larva received daily $100 \mu \mathrm{l}$ of a solution of water and fish food with the amount of food varying over the days. The standard diet was on hatching day: $0.04 \mathrm{mg}$ Tetramin ${ }^{\mathrm{TM}}$ baby fish food (Qualipet, Neuchatel, Switzerland) per larva; 1 day after hatching: $0.06 \mathrm{mg}$; 2 days: $0.08 \mathrm{mg}$; 3 days: $0.16 \mathrm{mg}$; 4 days: $0.32 \mathrm{mg}, 5$ days or later: $0.6 \mathrm{mg}$ [26].

Each pupa was put into a $180 \mathrm{ml}$ plastic cup (VWR International S.a.r.l., Nyon, Switzerland) covered with netting. Emerged females had access to $10 \%$ sugar solution and were held in an insectary at $26 \pm 1{ }^{\circ} \mathrm{C}, 70 \pm 5 \% \mathrm{RH}$ and a 12:12 $\mathrm{h}$ light:dark cycle, before the blood meal.

\section{Blood meal}

Four to five days after emergence, females were given the opportunity to feed on a mouse for $10 \mathrm{~min}$. The mice were obtained from the Institute of Cell Biology, University of Bern, Switzerland, and had been anaesthetized by intra-peritoneal injection of $8.5 \mathrm{ml} / \mathrm{kg}$ mix of 
${\text { Xylazine } \text { Xylasol }^{\circ}(20 \mathrm{mg} / \mathrm{ml}) \text {, Ketamine Ketasol }}^{\circ}$ (100 $\mathrm{mg} / \mathrm{ml}$ ) and phosphate buffered saline (PBS). One day after the blood meal, individual fully engorged mosquitoes (187 out of 303) were transferred into cups with $10 \%$ sugar solution and then, for logistical reasons, moved to an insectary at $19 \pm 1{ }^{\circ} \mathrm{C}$.

\section{Longevity and body size}

Longevity was measured as the time between the blood meal and death, which was assessed every $24 \mathrm{~h}$. Survival after a first blood meal is not the same as lifespan from birth but taking a bloodmeal is a realistic behavior. Besides, one of the key factors in vectorial capacity is how long a mosquito can survive after a potential infectious blood meal, which has motivated a history of interest and studies on mosquitoes' longevity post-blood meal. Larger individuals are more efficient at accumulating reserves used for fecundity, but blood meals are also used to synthesize lipids, which are used by female $A n$. gambiae both for flight as well as for survival $[19,27]$.

Wing length was used as a proxy for body size. Both wings of each individual were measured from the tip to the distal end of the alula [28] with the software Image J (version 1.47f7); we used the mean length of the two wings in our analyses.

\section{Analyses}

\section{Effect of the larval environment on the time to pupation}

We analysed the time to pupation of female mosquitoes depending on the larval environment by using a gaussian generalised linear model (GLM) of time to pupation regarding the larval diet and the larval temperature and the interaction between these factors.

\section{Relationship between wing length and survival}

We analysed how wing length was related to longevity depending on the larval environment. As body size is in part determined by the environment, and potentially associated with longevity, we ran our analysis in two steps.

We first analysed the direct effects of the environment on wing length with an ANOVA and on longevity with a Cox proportional hazards survival analysis, including temperature, food and their interaction as factors for both analyses.

We then did a separate analysis where we estimated the direct and indirect (via wing length) effects of food and temperature on longevity in a single model with a piece-wise structural equation model (SEM) [29]. This approach relies on a set of linear equations that are evaluated individually in the model and that are described below. This recent SEM method, and the associated $\mathrm{R}$ package, enable the use of the current statistical methods like generalised linear models or mixed effects models in the classical causal network of SEM. Worked examples and a detailed description of how this approach differs from classical SEM methods can be found in a recent paper [29]. It is different to classical SEM methods that are based on covariances among variables.

In our first analysis wing length was not affected by an interaction of food and temperature (see results), so we modelled the direct effects of the environment on wing length. We analysed wing length regarding the larval diet and the larval temperature without interactions between these factors. This is expressed as the following equation:

$$
\text { wing length food + temperature }
$$

Since we were interested in how food and temperature influenced the relationship between body size and longevity, we analysed longevity regarding the interactions between larval diet, larval temperature and wing length. Food and temperature were considered as factors and wing length a covariate. It gives the following equation:

$$
\text { longevity wing length } * \text { food } * \text { temperature }
$$

Analyses were done in $\mathrm{R}$ version 3.4.1. The SEM was implemented with the piecewiseSEM package [29].

\section{Results}

\section{Time to pupation}

The mean time to pupation decreased with the increase in temperature $\left(\chi^{2}=612.09, d f=1, P<0.0001\right)$, from 9.2 \pm 0.05 (mean \pm standard error, SE) days at $21{ }^{\circ} \mathrm{C}$, to 8.3 \pm 0.04 days at $25^{\circ} \mathrm{C}$ and $7.8 \pm 0.05$ days at $29^{\circ} \mathrm{C}$ (Fig. 1 ).

The mean time to pupation increased when the larval diet decreased by $50 \%$ (low diet) $\left(\chi^{2}=392.30, d f=1, P<\right.$ 0.0001 ), from $8.0 \pm 0.04$ days at standard diet to $8.85 \pm$ 0.05 days at low diet (Fig. 1 ).

There was also a significant interaction between the effect of temperature and larval diet (Table 1 and Fig. 1), $\left(x^{2}=6.61, d f=1, P=0.01\right)$. The pupation time increased by nearly 2.5 days between $29^{\circ} \mathrm{C}$ and standard food, and $21{ }^{\circ} \mathrm{C}$ and low food (respectively $7.17 \pm 0.03$ days and $9.65 \pm 0.07$ days). If only one environmental variable was modified (just food or just temperature) then the variation in pupation time was only up to 1.4 days. Modifying both the temperature and the food levels changed the pupation time more than modifying only one of the environmental factors.

\section{Relationship between longevity and size}

Mosquitoes reared at half the standard larval diet had shorter wings $(3.02 \pm 0.021 \mathrm{~mm})$ than those with the standard diet $(3.24 \pm 0.018 \mathrm{~mm})\left(F_{(1,181)}=90.1, P<0.0001\right)$. Wing length decreased with increasing temperature from $3.27 \mathrm{~mm}( \pm 0.032)$ at $21{ }^{\circ} \mathrm{C}$, to $3.23 \mathrm{~mm}( \pm 0.022)$ at $25^{\circ} \mathrm{C}$, and $3.02 \mathrm{~mm}( \pm 0.019)$ at $29{ }^{\circ} \mathrm{C}\left(F_{(2,181)}=35.7, P<\right.$ $0.0001)$. The effect of temperature was similar at the two 


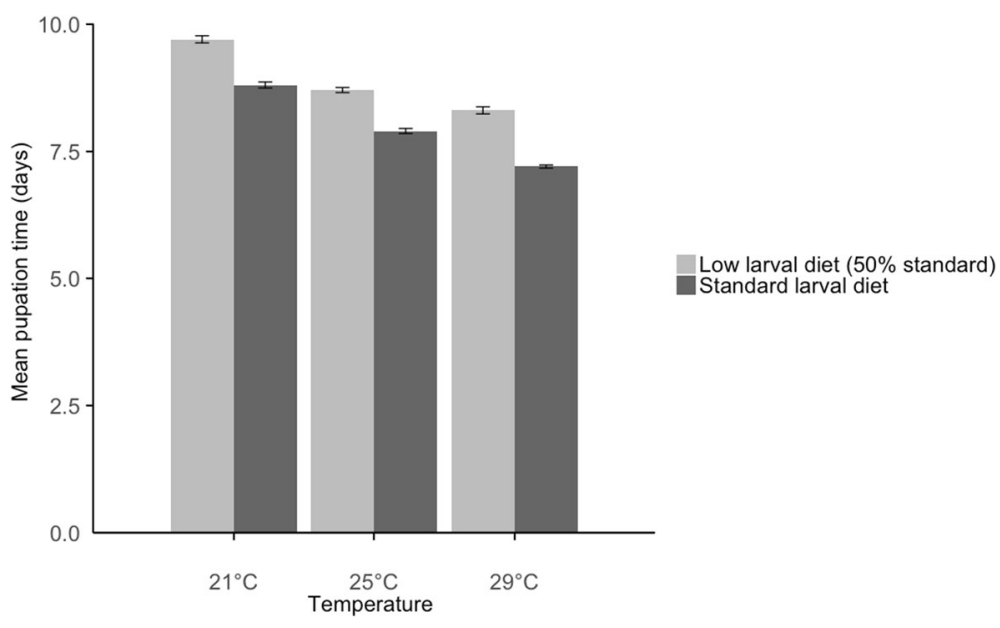

Fig. 1 Mean female mosquito pupation time (in days) \pm standard error, by larval rearing temperature $\left(21,25\right.$ and $29^{\circ} \mathrm{C}$ ) and level of larval nutrition (low, standard). The standard diet was on hatching day: $0.04 \mathrm{mg}$ Tetramin baby fish food per larva; 1 day after hatching: $0.06 \mathrm{mg} ; 2$ days: $0.08 \mathrm{mg} ; 3$ days: $0.16 \mathrm{mg} ; 4$ days: $0.32 \mathrm{mg} ; 5$ days or later: $0.6 \mathrm{mg}$. The low diet was 50\% of the standard. Larvae were reared at constant temperatures, at 21,25 or $29^{\circ} \mathrm{C}, 70 \pm 5 \% \mathrm{RH}$ and a $12: 12 \mathrm{~h}$ light:dark cycle

food levels (Fig. 2) so the interaction between food and temperature was not significant $\left(F_{(2,181)}=0.7, P=0.49\right)$.

Longevity ranged from 26.4 days $( \pm 2.54)$ for mosquitoes reared at $21{ }^{\circ} \mathrm{C}$ and standard food to 30.6 days $( \pm 1.56)$ for mosquitoes reared at $29{ }^{\circ} \mathrm{C}$ and low food (Fig. 3). However, longevity was not significantly influenced by temperature, larval nutrition, or their interaction (Cox proportional hazards: all $P>0.35$ ).

The piecewise structural equation model, fitting our data satisfactorily (Fisher's $C=2.3, d f=2, P=0.32$ ), confirmed the direct effects of food and temperature during larval development on body size, and confirmed the lack of direct effects of food and temperature on longevity (Table 2 and Fig. 4).

There were, however, indirect effects, which differed among environments. Thus, although overall no significant relationship was apparent between longevity and wing length (Figs. 4 and 5), there was a significant three-way interaction between wing length, food and temperature (Table 2). At $25^{\circ} \mathrm{C}$, longevity was only slightly related to wing length. At $29^{\circ} \mathrm{C}$ longevity was positively related to wing length at low food but negatively at standard

Table 1 Mean pupation time (in days) per larval temperature and larval diet

\begin{tabular}{llll}
\hline Larval T $\left({ }^{\circ} \mathrm{C}\right)$ & Larval diet & Mean pupation time (days) & SE \\
\hline 21 & Standard & 8.8 & 0.06 \\
21 & Low & 9.7 & 0.07 \\
25 & Standard & 7.9 & 0.05 \\
25 & Low & 8.7 & 0.05 \\
29 & Standard & 7.2 & 0.03 \\
29 & Low & 8.3 & 0.07 \\
\hline
\end{tabular}

Abbreviations: SE standard error, $T$ temperature food, whereas at $21{ }^{\circ} \mathrm{C}$ the slope was negative at low food but positive at standard food (Fig. 6). No other pathways were significant (see Table 2).

\section{Discussion}

While the overall relationship between mosquito size and longevity was weak, this relationship was apparent within individual larval treatments with the correlation between the two traits ranging from positive to negative among different treatments. At $25{ }^{\circ} \mathrm{C}$, the relationship was weak. At $29{ }^{\circ} \mathrm{C}$ the relationship was negative at standard food and positive with low food. At $21{ }^{\circ} \mathrm{C}$ it was negative at low food and positive at standard food. Thus, this confirms our hypothesis that the relationship between size and longevity is not limited to a positive correlation and that the environment affects this relationship. The mechanisms underlying the changes of the slope and the direction of the correlation between environments are still unclear, and future experiments that delve into the physiological basis of this are warranted.

The increase in temperature decreases both the time to pupation and the adult size while a decrease in larval diet decreases mosquito size but increases development time. While we were not able to directly link adult size and development time in our data, it confirms that traits may react differently to the larval environment [4, 6-9].

One idea underlying the relationship between body size and longevity is that longevity is related to the teneral reserves carried over from the juvenile stages to adulthood. Consequently, larger mosquitoes should have more reserves [18] and therefore survive longer and it would be interesting to explore this further in the absence of adult nutrition or water availability. Variation in 


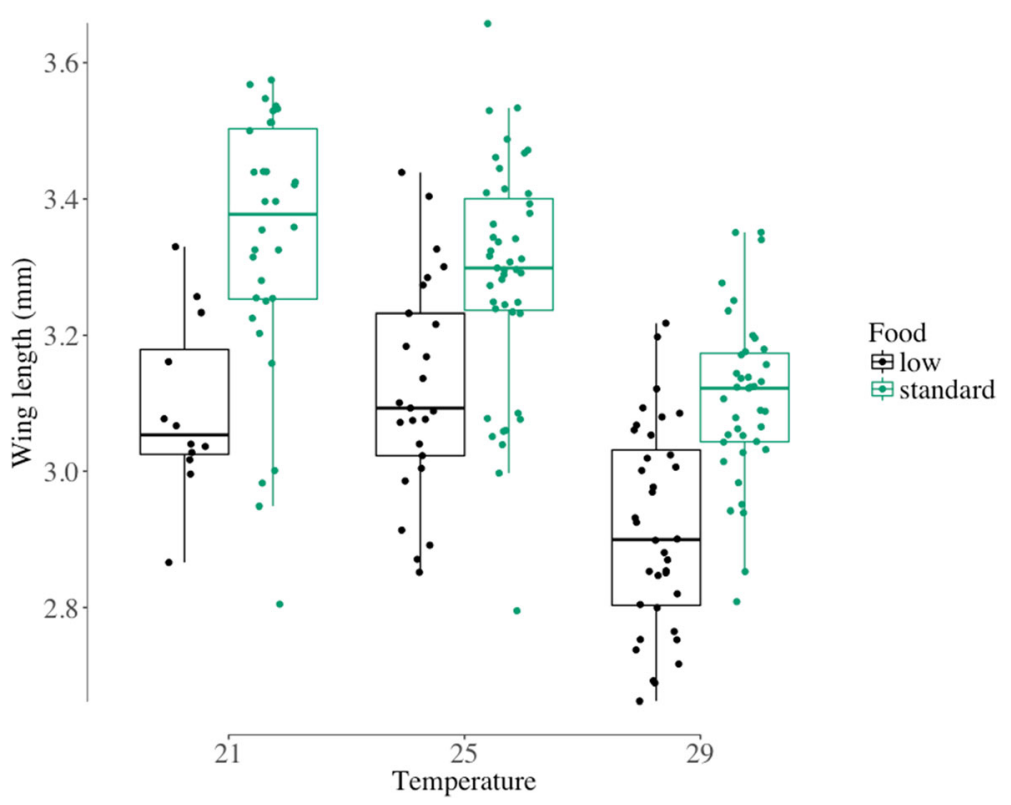

Fig. 2 Distribution of female mosquito wing length (in $\mathrm{mm}$ ) by larval rearing temperature $\left(21,25\right.$ and $29^{\circ} \mathrm{C}$ ) and level of larval nutrition (low, standard). The standard diet was on hatching day: $0.04 \mathrm{mg}$ Tetramin baby fish food per larva; 1 day after hatching: 0.06 mg; 2 days: 0.08 mg; 3 days: $0.16 \mathrm{mg} ; 4$ days: $0.32 \mathrm{mg} ; 5$ days or later: $0.6 \mathrm{mg}$. The low diet was $50 \%$ of the standard. Larvae were reared at constant temperatures, at 21 , 25 or $29^{\circ} \mathrm{C}, 70 \pm 5 \% \mathrm{RH}$ and a $12: 12 \mathrm{~h}$ light:dark cycle

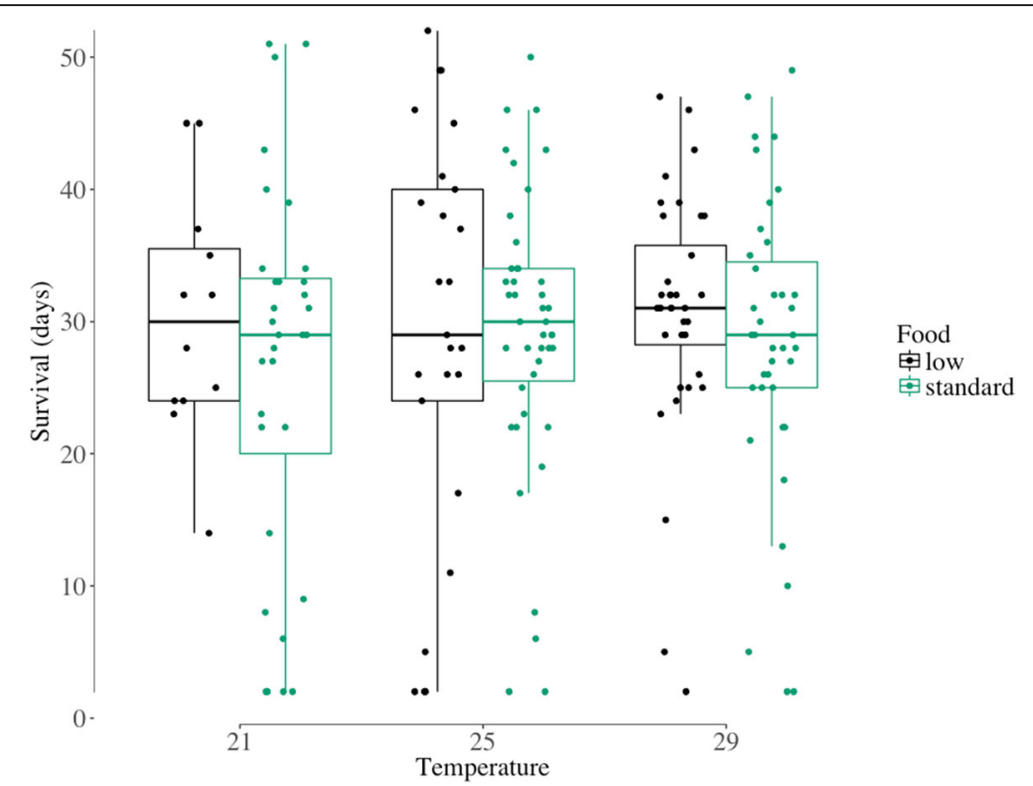

Fig. 3 Distribution of female mosquito longevity (in days) by larval rearing temperature $\left(21,25\right.$ and $29^{\circ} \mathrm{C}$ ) and level of larval nutrition (low, standard). Longevity is here the number of days between the blood meal and death for each female mosquito. The standard diet was on hatching day: $0.04 \mathrm{mg}$ Tetramin baby fish food per larva; 1 day after hatching: $0.06 \mathrm{mg} ; 2$ days: $0.08 \mathrm{mg} ; 3$ days: 0.16 mg; 4 days: 0.32 mg; 5 days or later: $0.6 \mathrm{mg}$. The low diet was $50 \%$ of the standard. Larvae were reared at constant temperatures, at 21,25 or $29{ }^{\circ} \mathrm{C}, 70 \pm 5 \% \mathrm{RH}$ and a $12: 12$ h light:dark cycle 
Table 2 Standardized regression coefficients of the structural equation model

\begin{tabular}{|c|c|c|c|c|}
\hline Response & Predictor & Estimate & SE & $P$-value \\
\hline Wing length (wl) & Food (standard) & 0.89 & 0.11 & $<0.001$ \\
\hline Wing length (wl) & Temperature (29) & -1.00 & 0.14 & $<0.001$ \\
\hline Wing length (wl) & Temperature (25) & -0.12 & 0.14 & 0.41 \\
\hline Longevity & $\mathrm{wl} *$ food $($ standard $) *$ temperature $(29)$ & -1.43 & 0.66 & 0.031 \\
\hline Longevity & $\mathrm{wl} *$ food (standard) & 0.84 & 0.54 & 0.12 \\
\hline Longevity & Food (standard) & -0.56 & 0.41 & 0.16 \\
\hline Longevity & $\mathrm{wl} *$ food $($ standard $) *$ temperature $(25)$ & -0.88 & 0.64 & 0.16 \\
\hline Longevity & $w l *$ temperature $(29)$ & 0.68 & 0.56 & 0.23 \\
\hline Longevity & Food (standard) * temperature $(25)$ & 0.54 & 0.50 & 0.28 \\
\hline Longevity & Temperature (29) & 0.42 & 0.45 & 0.36 \\
\hline Longevity & $\mathrm{wl}$ * temperature $(25)$ & 0.50 & 0.57 & 0.38 \\
\hline Longevity & $w l$ & -0.42 & 0.50 & 0.40 \\
\hline Longevity & Temperature (25) & 0.03 & 0.38 & 0.94 \\
\hline Longevity & Food (standard) * temperature (29) & 0.03 & 0.54 & 0.96 \\
\hline
\end{tabular}

The estimate column gives the standardized regression coefficient associated with the predictors, or their interactions (For example, it shows the difference of the regression coefficients of longevity on size for certain foods and temperature, for the triple interactions). The $P$-values in bold text are inferior to 0.05 and indicate significant predictors

larval food affects adult mosquito reserves and resistance to desiccation with consequences for survival [30].

One explanation for the complexity of the relationship, instead of having just a positive correlation between size and longevity, is that temperature influences the teneral reserves and wing length differently during larval development. Indeed, in Aedes albopictus (Diptera: Culicidae) the relationship between teneral lipids and body size is

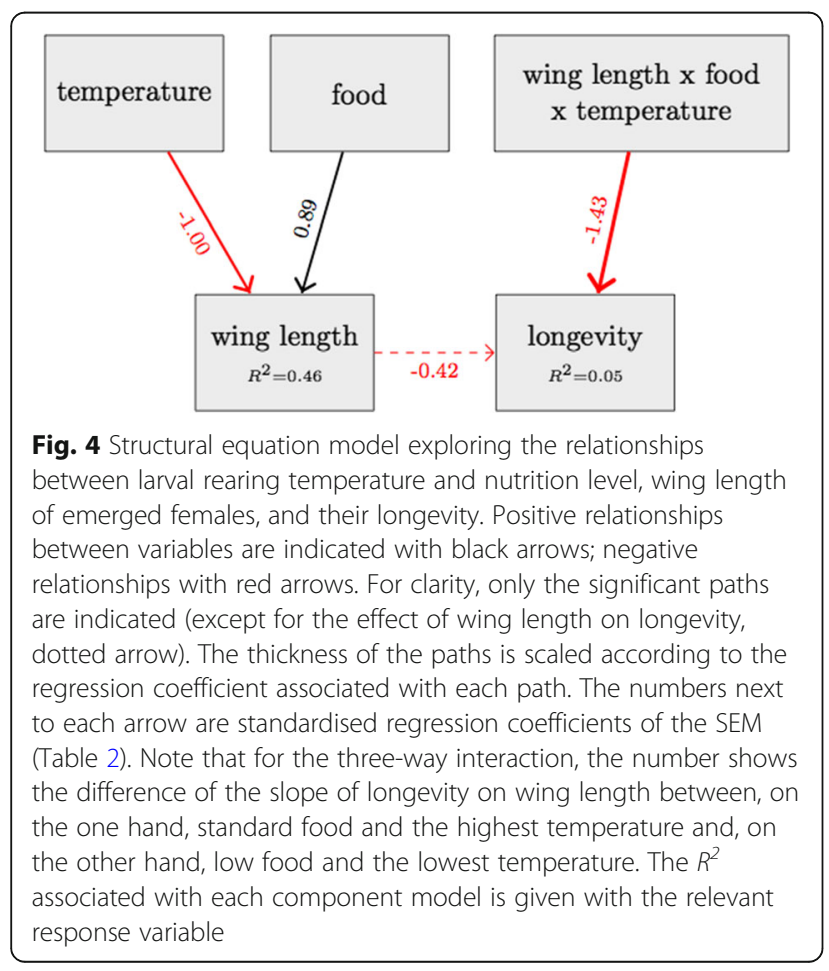

linear with warm temperatures during larval development and exponential at lower temperatures [31]. In $A n$. gambiae the relation between weight and wing length also varies with the temperature of the larval environment [32].

Another explanation is that the larval temperature and food levels influence the feeding behaviour of adults (blood and sugar consumption), which could have a large effect on longevity. There is, for example, a positive correlation between the larval food levels and the blood meal volume in An. gambiae [33]. The larval environment influences mosquito body size, and size affects the first meal choice of mosquitoes with smaller mosquitoes being more likely to take a sugar meal [34]. In addition,

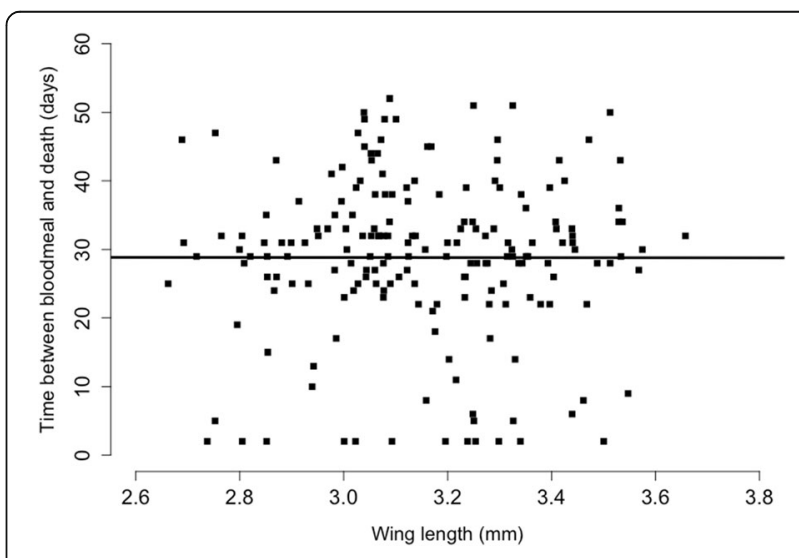

Fig. 5 Mosquito longevity (in days) as a function of mosquito wing length (in $\mathrm{mm}$ ). Each point shows the time between the blood meal and death of a female mosquito (longevity). The solid line represents the regression of longevity on wing length 


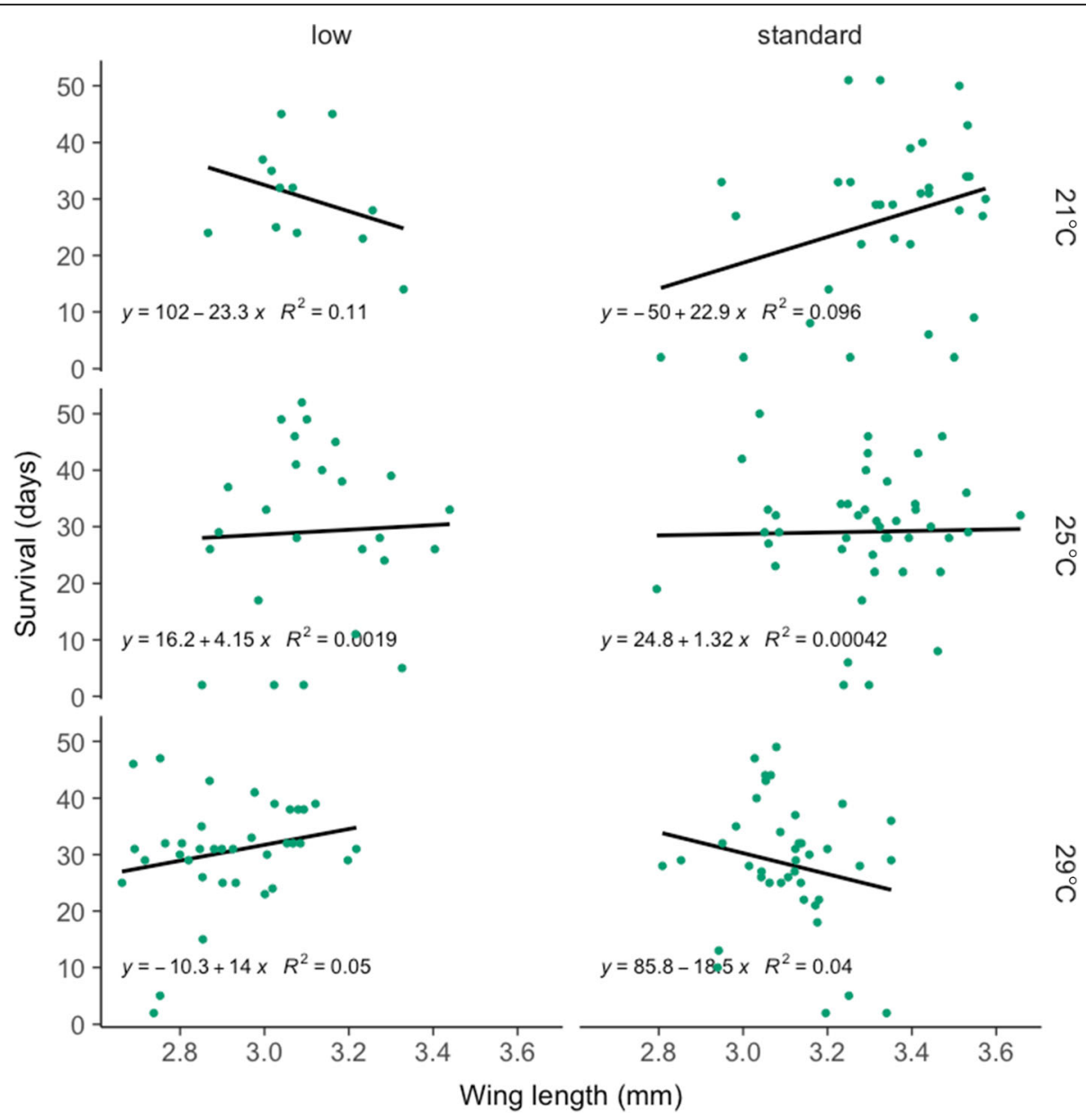

Fig. 6 Mosquito longevity (in days) as a function of wing length (in $\mathrm{mm}$ ) by larval rearing temperature $\left(21,25\right.$ and $29^{\circ} \mathrm{C}$ ) and level of larval nutrition (low, standard). Longevity is here the number of days between the blood meal and death for each female mosquito. The standard diet was on hatching day: $0.04 \mathrm{mg}$ Tetramin baby fish food per larva; 1 day after hatching: 0.06 mg; 2 days: 0.08 mg; 3 days: 0.16 mg; 4 days: 0.32 mg; 5 days or later: $0.6 \mathrm{mg}$. The low diet was $50 \%$ of the standard. Larvae were reared at constant temperatures, at 21,25 or $29{ }^{\circ} \mathrm{C}, 70 \pm 5 \% \mathrm{RH}$ and a 12:12 h light:dark cycle. The equation of the regression of longevity on wing length is given in each panel along with the $R^{2}$ value

larger female mosquitoes accumulate reserves from blood meals more efficiently and need fewer blood meals to develop mature eggs [19]. Such differences in feeding regimes may also impact the effectiveness of vector control due to the variability in exposure to classical vector control tools like long-lasting insecticide-treated nets (LLIN) or indoor residual spraying (IRS) or new tools like attractive-toxic sugar baits (ATSB) [35], raising further the importance of understanding the influence of the larval environment.

Adult mosquitoes were kept at the constant temperature of $19 \pm 1{ }^{\circ} \mathrm{C}$, after the blood meal, which is at the lower part of the temperature range for adult An. gambiae mosquitoes and malaria transmission, 17 to $40{ }^{\circ} \mathrm{C}$ [36-39]. Repeating this study at higher or fluctuating temperatures may modify the relationship observed here, as constant and fluctuating adult temperatures are known to influence adult survival with increased longevity at lower temperatures [20, 40, 41]. The use of a low temperature with increased longevity is a conservative choice, as if the observed association between longevity and body size vary with different larval environments for a low adult temperature, they may just vary even more at higher temperatures.

Larvae were reared in the laboratory using larval diet based on previous studies $[26,42]$ and it is possible that even half our standard diet is still too comfortable for An. gambiae mosquitoes compared to natural conditions. Larvae are filter-feeders and what they feed on in natural conditions remains unclear [43]. The presence of algae increases mosquito density, especially for the last larval stages [44], and larvae prefer sunny sites with little aquatic vegetation that are favourable to algal growth [45]. Even if the laboratory diets have some differences with the hypothesised natural diets, we would then expect a greater effect of more variation in larval diets or 
harsher natural conditions on the correlations between adult body size and longevity.

Another important factor of vectorial capacity in addition to longevity or survival, is vector competence, which also depends on the body size of the vector and the larval environment [16]. For instance, smaller Aedes aegypti mosquitoes can be either more [46] or less [47] resistant to dengue virus. This relationship is influenced by larval density in both studies, but it changes from negative to positive by adding the effect of larval competition in the second study [47].

For evolutionary considerations, it would be important to also look at fecundity. Other studies suggest that the relationship between size and fecundity depends less on the environment: smaller mosquitoes are less fecund independently of temperature or food $[9,48]$. However, how body size affects reproductive success (the combination of fecundity and longevity) in different environments is not known but would be critical for understanding the evolution of mosquito life history and the consequences on malaria transmission.

\section{Conclusions}

To conclude, the relation between size and longevity differed among larval environments, with larger mosquitoes living longer in some environments but less long in others. This confirmed our hypothesis that the relationship between size and longevity is not limited to a positive correlation and that the interaction between environmental factors can change the slope and the direction of the relationship. A better understanding of this complexity and its mechanisms is necessary to understand and model the evolution of the life history traits of mosquitoes, the transmission of mosquito-borne diseases, and the influence on vector control.

\section{Additional files}

Additional file 1: Table S1. Wing length and longevity per larval environment dataset. (XLS $42 \mathrm{~kb}$ )

Additional file 2: Table S2. Pupation time per larval environment dataset. (XLS $80 \mathrm{~kb}$ )

Additional file 3: Script for the piecewise SEM in R. The script is to be used with the Additional file 1. The first part of the script enables the user to install all the necessary packages and to import the dataset. The rest of the script enables the user to realise the piecewise SEM. The different steps are detailed from creating the model to obtaining the standardised regression coefficients. (R $1 \mathrm{~kb})$

\section{Abbreviations}

GLM: Generalised linear model; IRS: Indoor residual spraying; LLIN: Longlasting insecticide-treated nets; PBS: Phosphate-buffered saline; SE: Standard error; SEM: Structural equation model

\section{Acknowledgments}

We thank Volker Heussler for providing the mice and Olivier Rais for helping to blood-feed mosquitoes.

\section{Funding}

AMGB, PB and JCK were supported by the University of Neuchâtel to design the study, collect the data, analyse it, and write the manuscript. AMGB and PB were also supported by the Bill \& Melinda Gates Foundation, Grant Number: OPP1131603 when interpreting the data further and writing the manuscript. CMS was supported by the Illinois Waste Tire and Emergency Public Health funds to analyse the data and contribute to the manuscript.

\section{Availability of data and materials}

The data supporting the conclusions of this article are included within the article and its additional files. The longevity and body size dataset supporting the conclusions of this article is included within the Additional file 1. The time to pupation data are available in Additional file 2. The code for the piecewise SEM analysis is available as a.R file in the Additional file 3. It is modified from the code of a worked example by Lefcheck [29] and from the github webpage: https://github.com/jslefche/piecewiseSEM.

\section{Authors' contributions}

$A M G B$ and $P B$ carried out the laboratory work and collected data. AMGB, PB and JCK designed the study. AMGB, CMS and JCK analysed the data. All authors helped draft the manuscript. All authors read and approved the final manuscript.

\section{Ethics approval}

Procedures involving mice were conducted in accordance with the Swiss Tierschutzgesetz guidelines (Animal Rights Laws) and approved by the Ethical Committee of the University of Bern (Permit Number: BE109/13)

Consent for publication

Not applicable.

\section{Competing interests}

The authors declare that they have no competing interests.

\section{Publisher's Note}

Springer Nature remains neutral with regard to jurisdictional claims in published maps and institutional affiliations.

\section{Author details}

${ }^{1}$ Center for Infectious Disease Dynamics and Department of Entomology, Pennsylvania State University, University Park, PA 16802, USA. ²aboratory of Ecology and Epidemiology of Parasites, Institute of Biology, University of Neuchâtel, Rue Emile-Argand 11, 2000 Neuchâtel, Switzerland. ${ }^{3}$ Illinois Natural History Survey, University of Illinois, Champaign, IL 61820, USA.

Received: 26 April 2018 Accepted: 10 August 2018 Published online: 29 August 2018

References

1. Paaijmans KP, Read AF, Thomas MB. Understanding the link between malaria risk and climate. Proc Natl Acad Sci. 2009;106:13844-9.

2. Rochlin I, Faraji A, Ninivaggi DV, Barker CM, Kilpatrick AM. Anthropogenic impacts on mosquito populations in North America over the past century. Nat Commun. 2016;7:13604.

3. Livdahl TP, Sugihara G. Non-linear interactions of populations and the importance of estimating per capita rates of change. J Anim Ecol. 1984;53: 573-80

4. Reiskind $\mathrm{MH}$, Lounibos LP. Effects of intraspecific larval competition on adult longevity in the mosquitoes Aedes aegypti and Aedes albopictus. Med Vet Entomol. 2009;23:62-8.

5. Roux O, Vantaux A, Roche B, Yameogo KB, Dabiré KR, Diabaté A, et al. Evidence for carry-over effects of predator exposure on pathogen transmission potential. Proc Biol Sci. 2015;282:20152430.

6. Bar-Zeev M. The effect of temperature on the growth rate and survival of the immature stages of Aedes aegypti (L.). Bull Entomol Res. 1958;49:157.

7. Lyimo EO, Takken W, Koella JC. Effect of rearing temperature and larval density on larval survival, age at pupation and adult size of Anopheles gambiae. Entomol Exp Appl. 1992;63:265-71.

8. Gimnig JE, Ombok M, Otieno S, Kaufman MG, Vulule JM, Walker ED. Densitydependent development of Anopheles gambiae (Diptera: Culicidae) larvae in artificial habitats. J Med Entomol. 2002;39:162-72. 
9. Vantaux A, Lefèvre T, Cohuet A, Dabiré KR, Roche B, Roux O. Larval nutritional stress affects vector life history traits and human malaria transmission. Sci Rep. 2016;6:36778.

10. Hagstrum DW, Workman EB. Interaction of temperature and feeding rate in determining the rate of development of larval Culex tarsalis (Diptera, Culicidae). Ann Entomol Soc Am. 1971;64:668-71.

11. Padmanabha H, Bolker B, Lord CC, Rubio C, Lounibos LP. Food availability alters the effects of larval temperature on Aedes aegypti growth. J Med Entomol. 2011;48:974-84

12. Reiskind MH, Janairo MS. Late-instar behavior of Aedes aegypti (Diptera: Culicidae) larvae in different thermal and nutritive environments. J Med Entomol. 2015;52:789-96.

13. Reiskind MH, Janairo MS. Tracking Aedes aegypti (Diptera: Culicidae) larval behavior across development: effects of temperature and nutrients on individuals' foraging behavior. J Med Entomol. 2018. https://doi.org/10.1093/ jme/tjy073.

14. Ellner SP, Rees M. Integral projection models for species with complex demography. Am Nat. 2006;167:410-28.

15. Stearns SC. Life-history tactics: a review of the ideas. Q Rev Biol. 1976;51:3-47.

16. Barreaux AMG, Barreaux P, Thievent K, Koella JC. Larval environment influences vector competence of the malaria mosquito Anopheles gambiae. MWJ. 2016;7:8

17. Cohuet A, Harris C, Robert V, Fontenille D. Evolutionary forces on Anopheles: what makes a malaria vector? Trends Parasitol. 2010;26:130-6.

18. Briegel $\mathrm{H}$. Metabolic relationship between female body size, reserves, and fecundity of Aedes aegypti. J Insect Physiol. 1990;36:165-72.

19. Takken W, Klowden MJ, Chambers GM. Effect of body size on host seeking and blood meal utilization in Anopheles gambiae sensu stricto (Diptera: Culicidae): the disadvantage of being small. J Med Entomol. 1998;35:639-45.

20. Christiansen-Jucht C, Parham PE, Saddler A, Koella JC, Basáñez M-G. Temperature during larval development and adult maintenance influences the survival of Anopheles gambiae s.s. Parasit Vectors. 2014;7:489.

21. Noden BH, O'Neal PA, Fader JE, Juliano SA. Impact of inter- and intraspecific competition among larvae on larval, adult, and life-table traits of Aedes aegypti and Aedes albopictus females. Ecol Entomol. 2016;41:192-200.

22. Zeller M, Koella JC. Effects of food variability on growth and reproduction of Aedes aegypti. Ecol Evol. 2016;6:552-9.

23. Stearns SC. The Evolution of Life Histories. Oxford: Oxford University Press; 1992.

24. Heilbronn LK, Ravussin E. Calorie restriction and aging: review of the literature and implications for studies in humans. Am J Clin Nutr. 2003;78: 361-9.

25. Atkinson D. Temperature and organism size - a biological law for ectotherms? Adv Ecol Restor. 1994:25:1-58.

26. Kulma K, Saddler A, Koella JC. Effects of age and larval nutrition on phenotypic expression of insecticide-resistance in Anopheles mosquitoes. PLoS One. 2013;8:e58322

27. Kaufmann C, Briegel H. Flight performance of the malaria vectors Anopheles gambiae and Anopheles atroparvus. J Vector Ecol. 2004;29:140-53.

28. Barreaux AMG, Barreaux P, Koella JC. Overloading the immunity of the mosquito Anopheles gambiae with multiple immune challenges. Parasit Vectors. 2016:9:210.

29. Lefcheck JS. PIECEWISESEM: Piecewise structural equation modelling in $\mathrm{R}$ for ecology, evolution, and systematics. Methods Ecol Evol. 2016;7:573-9.

30. Aboagye-Antwi F, Tripet F. Effects of larval growth condition and water availability on desiccation resistance and its physiological basis in adult Anopheles gambiae sensu stricto. Malar J. 2010;9:225.

31. Briegel H, Timmermann SE. Aedes albopictus (Diptera: Culicidae): physiological aspects of development and reproduction. J Med Entomol. 2001;38:566-71.

32. Koella JC, Lyimo EO. Variability in the relationship between weight and wing length of Anopheles gambiae (Diptera: Culicidae). J Med Entomol. 1996:33:261-4

33. Takken W, Smallegange RC, Vigneau AJ, Johnston V, Brown M, MordueLuntz AJ, et al. Larval nutrition differentially affects adult fitness and Plasmodium development in the malaria vectors Anopheles gambiae and Anopheles stephensi. Parasit Vectors. 2013;6:345.

34. Stone CM, Jackson BT, Foster WA. Effects of bed net use, female size, and plant abundance on the first meal choice (blood vs sugar) of the malaria mosquito Anopheles gambiae. Malar J. 2012;11:3.
35. Barreaux P, Barreaux AMG, Sternberg ED, Suh E, Waite JL, Whitehead SA, et al. Priorities for broadening the Malaria Vector Control Tool Kit. Trends Parasitol. 2017;33:763-74.

36. Bayoh MN. Studies on the development and survival of Anopheles gambiae sensu stricto at various temperatures and relative humidities. Durham: PhD thesis, Durham University; 2001

37. Mordecai EA, Paaijmans KP, Johnson LR, Balzer C, Ben-Horin T, de Moor E, et al. Optimal temperature for malaria transmission is dramatically lower than previously predicted. Ecol Lett. 2013;16:22-30.

38. Shapiro LLM, Whitehead SA, Thomas MB. Quantifying the effects of temperature on mosquito and parasite traits that determine the transmission potential of human malaria. PLoS Biol. 2017;15:e2003489.

39. Beck-Johnson LM, Nelson WA, Paaijmans KP, Read AF, Thomas MB, Bjørnstad ON. The effect of temperature on Anopheles mosquito population dynamics and the potential for malaria transmission. PLoS One. 2013;8: e79276.

40. Lyons CL, Coetzee M, Chown SL. Stable and fluctuating temperature effects on the development rate and survival of two malaria vectors, Anopheles arabiensis and Anopheles funestus. Parasit Vectors. 2013;6:104.

41. Paaijmans KP, Blanford S, Bell AS, Blanford JI, Read AF, Thomas MB. Influence of climate on malaria transmission depends on daily temperature variation. Proc Natl Acad Sci. 2010;107:15135-9.

42. Koella JC, Sorensen FL. Effect of adult nutrition on the melanization immune response of the malaria vector Anopheles stephensi. Med Vet Entomol. 2002;16:316-20.

43. Godfray HCJ. Mosquito ecology and control of malaria. J Anim Ecol. 2013;82 $15-25$.

44. Tuno N, Githeko AK, Nakayama T, Minakawa N, Takagi M, Yan G. The association between the phytoplankton, Rhopalosolen species (Chlorophyta; Chlorophyceae), and Anopheles gambiae sensu lato (Diptera: Culicidae) larval abundance in western Kenya. Ecol Res. 2006;21:476-82.

45. Gimnig JE, Ombok M, Kamau L, Hawley WA. Characteristics of larval Anopheline (Diptera: Culicidae) habitats in western Kenya. J Med Entomol. 2001;38:282-8.

46. Sumanochitrapon W, Strickman D, Sithiprasasna R, Kittayapong P, Innis BL. Effect of size and geographic origin of Aedes aegypti on oral infection with denque-2 virus. Am J Trop Med Hyg. 1998;58:283-6.

47. Alto BW, Reiskind MH, Lounibos LP. Size alters susceptibility of vectors to dengue virus infection and dissemination. Am J Trop Med Hyg. 2008;79: 688-95.

48. Christiansen-Jucht CD, Parham PE, Saddler A, Koella JC, Basáñez M-G. Larval and adult environmental temperatures influence the adult reproductive traits of Anopheles gambiae s.s. Parasit Vectors. 2015;8:456.

\section{Ready to submit your research? Choose BMC and benefit from:}

- fast, convenient online submission

- thorough peer review by experienced researchers in your field

- rapid publication on acceptance

- support for research data, including large and complex data types

- gold Open Access which fosters wider collaboration and increased citations

- maximum visibility for your research: over $100 \mathrm{M}$ website views per year

At $\mathrm{BMC}$, research is always in progress.

Learn more biomedcentral.com/submissions 